\title{
Atmospheric Pressure Anomalies over Earthquakes Epicenters
}

\author{
Eladio Zárate Hernández and Mario Fernández Arce
}

\section{ABSTRACT}

This article is an analysis of the anomalies in atmospheric pressure days before and during the occurrence of earthquakes. The research started from the review of scientific articles in which it has been proposed that atmospheric events generate or trigger seismicity, and that earthquakes alter the atmosphere. Therefore, the atmospheric pressure pattern in Costa Rica during earthquakes with a magnitude greater than or equal to $6.5 \mathrm{Mw}$, for the period 1950 - 2020, was studied in order to investigate a possible link between atmospheric events and underground processes of the planet. For this, atmospheric pressure anomaly maps were drawn in which the epicenter of the earthquakes was located. Among the results, it stands out that $64 \%$ of the epicenters occurred in areas where the pressure anomaly had a value close to or equal to zero. This could indicate, as other authors have suggested, that atmospheric pressure alters the cortical stress pattern, thus contributing to the triggering of earthquakes.

Keywords: earthquakes, atmosphere, pressure anomalies, solid Earth.
Published Online: July 10, 2021

ISSN: $2684-446 \mathrm{X}$

DOI :10.24018/ejgeo.2021.2.4.150

Eladio Zárate Hernández

Escuela de Geografía, Universidad de Costa Rica, Costa Rica.

(e-mail: elzarate2003@yahoo.com)

Mario Fernández Arce *

Escuela de Geografía, Universidad de Costa Rica, Costa Rica.

(e-mail: mario.fernandezarce@ucr.ac.cr)

*Corresponding Author

\section{INTRODUCTION}

This article focuses on atmospheric pressure anomalies and the occurrence of earthquakes. Because Zárate [1] found earthquake epicenters near the zero-value isoline of wind anomalies, the researchers decided to study the behavior of the atmospheric pressure anomaly over Costa Rican earthquakes of magnitude $\geq 6.5$ from the last 70 years (1950 2020). The seismic parameters of these events were analyzed, as well as their geological environments and location. Meteorological data were used to identify anomalies in atmospheric pressure which occurred near the epicenters. Both the anomalies and the epicenters were transferred to maps to visualize possible associations.

Possible interactions between atmospheric processes and those of solid Earth have been identified and documented. Some researchers have indicated and shown that atmospheric pressure causes deformation of the earth's crust [2]-[5]. Seismic-ionospheric couplings have been proposed in several works [6]-[9]. Liu et al. [8] reported that the uplift associated to the 2004 Indonesian earthquake pushed the atmosphere upward causing the ionosphere to move $40 \mathrm{~km}$ up and down. Namias [10] confirmed that pressure and wind configurations over a wide portion of the northern hemisphere triggered (or decreased) moderate-magnitude seismicity in southern California. Walker [11], assuming that the meteorological phenomena call El Niño and the seismicity are related, interpreted that low atmospheric pressure trigger increased seismic activity.

Zharov [12] found a strong correlation between the changes of the atmospheric angular momentum functions and the times when earthquakes occur. Guillas et al. [13] suggested that the reduction of few kilopascal over the East Pacific Rise generates plate flexure that can trigger fault activity and seismicity. Nishida and Takagi [14] reported P and $\mathrm{S}$ wave microseisms triggered by an intense and distant storm in the North Atlantic over Greenland and Iceland. Zárate [1], [15] found epicenters of earthquakes and volcanic eruptions in the zones of almost zero wind anomaly. Fan et al. [16] discovered the stormquakes, that is, earthquakes generate by hurricanes. Finally, Fullerton et al. [17] suggest that subsurface bacterial community are probably affected by deep tectonic processes and that these communities could in turn impact the geosphere.

The mentioned publications provide new knowledge on possible solid earth - atmosphere interactions and on relationships between processes of the atmosphere and the Earth's interior. This paper is done to provide the scientific community new results that can be used in any other related research. Data provided could help other researchers to develop and create new investigations on possible reciprocal influences between the two fields contemplated in this study. Human being has finite knowledge on Earth and natural events still surprise us precisely because we do not know everything about Nature yet [18]-[20].

The work required a documentary review on the interaction between solid earth - atmosphere processes which forced to seek information in scientific journals. Seismic information on 11 earthquakes was extracted from the database of the National Seismological Network (RSN: ICE-UCR). Similarly, data on pressure anomalies were extracted from world meteorological bases. With these data, atmospheric 
anomalies were determined and transferred to maps together with the epicenter of the earthquakes. Such information was interpreted and analyzed to look for interrelations between the events of both fields.

All the seismic events occurred at moments when there were large scale pressure anomalies near the epicenters, 6 of them coincided with low pressure, 3 with high pressure and 2 with areas of low tropical pressure. A large percentage of the events occurred in areas where the anomalies of pressure had values of zero. This seems to suggest, as has already been proposed, that atmospheric pressure fields are connected with seismicity triggering.

\section{Methodology}

The research required documental review to know works and previous works that precede this publication. It included articles that have addressed the effects of seismic events in the atmosphere and also the impact of atmospheric processes on solid earth. This implied searching and reviewing scientific articles on changes in the ionosphere and in the atmosphere generated by earthquakes, the influence of alterations in the atmospheric angular momentum in seismicity triggering and the role of atmospheric events (storms and hurricanes) in the generation of earthquakes. We also reviewed articles containing information on moderate and large magnitude earthquakes that occurred in Costa Rica in the period 1950-2020.

The collection of seismological data required reviewing the databases of the National Seismological Network (RSN: ICE-UCR), an entity constituted by the University of Costa Rica (UCR) and the Costa Rican Electricity Institute (ICE). The criterion for choosing the earthquakes was the moment magnitude (Mw), with 6.5 as the lower threshold. The date of the events was of great importance to search the meteorological data later on. The data on epicenter's location was also relevant to graph them on maps of atmospheric pressure anomalies.

The pressure data were extracted from the National Oceanographic and Atmospheric Administration (NOAA) database, from the website of the Physical Sciences Division located in Boulder Colorado, which is: http://www.esrl.noaa.gov/psd/. In this work, emphasis is placed on pressure anomaly at synoptic scale. The Northern Hemisphere: $0-50 \mathrm{~N}, 40-120 \mathrm{~W}$ was used as the plotting region in a cylindrical projection. The sea level pressure anomalies were obtained with respect to the 1981-2010 climatology, where pressure data was plotted on a 2.5 degree $\times 2.5$ degree global grid. The pressure anomaly is obtained when the average value of the long-term daily pressure is subtracted from the pressure value that is actually occurring. The result can be positive, negative, or zero, and the more positive or negative the result, the greater the pressure anomaly. Pressure anomaly maps were constructed using a 1 $\mathrm{hPa}$ contour interval.

We used the graphical mode to visualize the possible relationship between atmospheric pressure anomalies and the occurrence of earthquakes. This mode included maps and figures that show both the spatial distribution of the atmospheric anomalies and the location of the epicenters. The so-called "zeros" of the pressure anomalies are a very small range of values between $\pm 1 \mathrm{hPa}$.

\section{REsults}

As previously stated, because Zarate [1], [15] found epicenters and volcanic eruptions near the zero-value isoline of the wind anomalies, the researchers found it interesting to analyze the behavior of atmospheric pressure over the epicenters of the largest Costa Ricans earthquakes of the last 70 years (Table I).

TABLE I: ATMOSPHERIC CHARACTERISTICS DURING 11 COSTA RICAN EARTHQUAKES FROM THE 1950-2020 PERIOD

\begin{tabular}{|c|c|c|c|c|c|c|}
\hline \multirow[t]{2}{*}{ Earthquake } & Day & Month & Year & \multicolumn{3}{|c|}{$\begin{array}{c}\text { Atmospheric } \\
\text { Event Type } \\
\text { (PZ) }\end{array}$} \\
\hline & 1 & 2 & 3 & 4 & 5 & 6 \\
\hline Nicoya & 5 & 10 & 1950 & 7.7 & $\mathrm{Lg}$ & 0.1 \\
\hline $\begin{array}{l}\text { Punta } \\
\text { Burica }\end{array}$ & 1 & 7 & 1979 & 6.5 & $\mathrm{Lg}$ & 0.4 \\
\hline Golfito* & 2 & 4 & 1983 & 7.2 & $\mathrm{Lg}$ & $-2,1$ \\
\hline Limón & 22 & 4 & 1991 & 7.7 & $\mathrm{Lg}$ & $-0,6$ \\
\hline Naranjo* & 7 & 3 & 1992 & 6.6 & $\mathrm{Lg}$ & -2.5 \\
\hline Quepos* & 20 & 8 & 1999 & 6.9 & $\mathrm{Lg}$ & 0.4 \\
\hline Tilarán* & 14 & 4 & 1973 & 6.5 & $\mathrm{Hg}$ & 0,6 \\
\hline Cóbano & 25 & 3 & 1990 & 6.8 & $\mathrm{Hg}$ & 1.8 \\
\hline Nicoya & 5 & 9 & 2012 & 7.6 & $\mathrm{Hg}$ & 1.3 \\
\hline Quepos & 9 & 9 & 1952 & 6.8 & Ltrop & $-0,5$ \\
\hline Sámara & 22 & 8 & 1978 & 7.0 & Ltrop & 0.0 \\
\hline
\end{tabular}

Note: Values for pressure anomalies are averages for 24-hour periods in UTC time. If an earthquake occurs before 12 UTC, the resulting map corresponds to the previous day and is marked with an asterisk on the date. Mw: Moment magnitude. PZ: Type of pressure zones. PA: Daily mean value of the surface pressure anomaly (hPa) at the epicenter on the day of the earthquake.

The configurations of the pressure anomalies at sea level on the day of the earthquakes were classified into three groups: areas of low general pressure type Lg, areas of high general pressure type $\mathrm{Hg}$ and areas of low tropical pressure type Ltrop (Table I). The $\mathrm{Lg}$ and $\mathrm{Hg}$ zones behave as opposite in configuration. In general terms, Lg-type low pressure zones (colors light blue, blue, lilac, purple in Fig. 1) tend to occupy large areas of North America, the Caribbean Sea, Central America and in some cases, the eastern tropical Pacific.

Of the 11 earthquakes analyzed, 6 coincided with Lg-type anomalies. They occurred practically on the edges of the lowpressure zones, most of them in the zone of zero pressure anomaly. The isolines of zero value of the pressure anomalies, that separate the positive values from the negative ones (white areas), tend to pass near the epicenters of the earthquakes (red dots). In four of the six Lg-type configurations the epicenters were located in the zero zone of the pressure anomalies. The epicenters out the zero zone, such as those of Golfito in 1983 and Naranjo in 1992, are in an area with values close to zero (-2.1 and 2.5, respectively, Table I). The 1992 Naranjo earthquake was a subduction earthquake whose epicenter was located $85 \mathrm{~km}$ deep. The influence of external forces on internal ones may be less at that depth. 

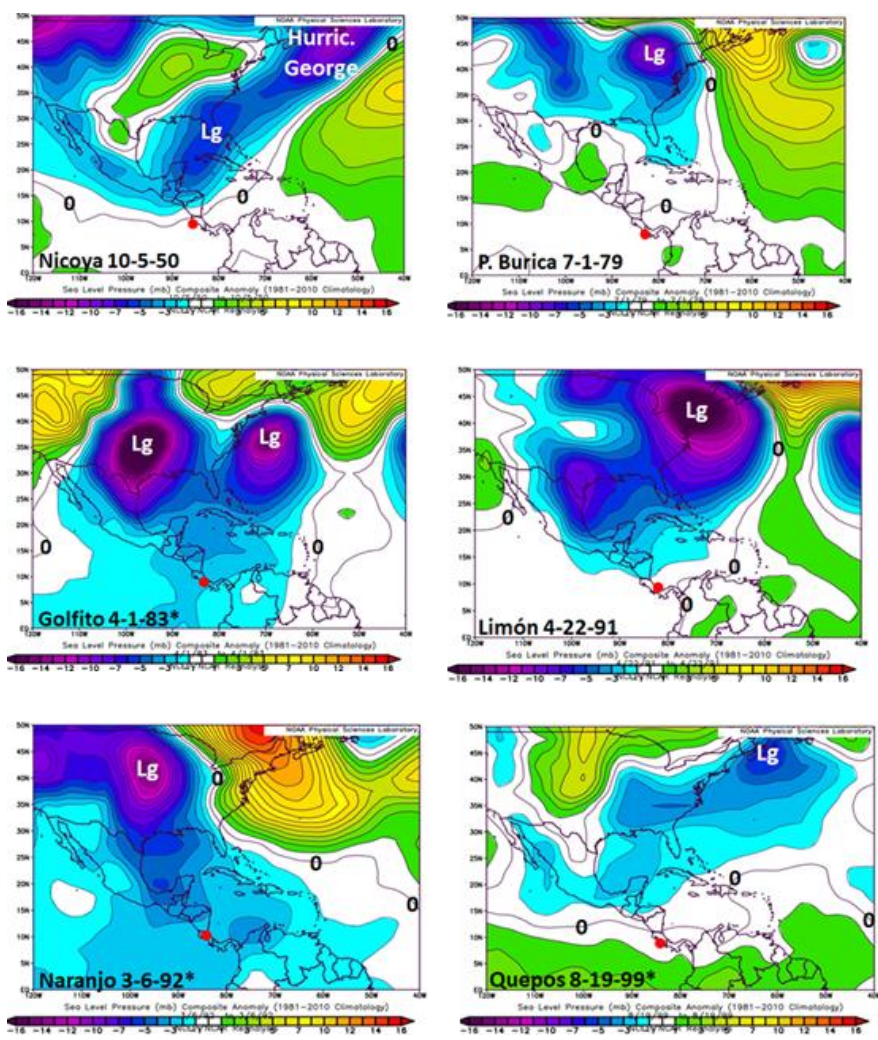

Fig. 1. Maps of pressure anomalies (hPa) for six Costa Rican earthquakes from the 1950-2020 period showing areas of general low pressure type Lg. Each map corresponds to the day of the earthquake, unless annotated with an asterisk, in which case the map corresponds to the previous day. The red dots indicate the epicenters.

Three of the 11 earthquakes studied coincided with high pressure areas of the general $\mathrm{Hg}$ type (Fig. 2). These Hg-type atmospheric configurations show high-pressure anomalies over North America, the Northwest Atlantic, the Caribbean, Central America, and sometimes over the eastern tropical Pacific, which is practically the opposite of Lg-type zones. They also show near-zero values in the pressure anomalies towards the south of Central America, similar to that shown for Lg-type.

The case of the Nicoya earthquake on September 5, 2012, deserves further explanation, since its map is something different from those of Tilarán and Cóbano. That appearance is due to the proximity of the Tropical Storm Leslie by the east side of the $\mathrm{Hg}$ area. Two days prior to the earthquake, the $\mathrm{Hg}$ structure was clear as the storm Leslie approached from the Atlantic. The good organization of the high-pressure area was evident (not shown) on the August 31-September 1 period but not on the September 4-5 period when it decreased in extension due to the approach of the storm. For the period
4-5 of September the $\mathrm{Hg}$ zone had lost extension and magnitude due to the advance of Leslie towards the west. Even so, it conserved the characteristics of an $\mathrm{Hg}$ zone, for which it was classified as such.

Two earthquakes occurred under atmospheric conditions of low tropical pressure, Ltrop type, in which negative pressure anomalies generally occupy the Caribbean Sea, Central America and the eastern tropical Pacific, as shown in Fig. 3. The Quepos 1952 and the Sámara 1978 earthquakes occurred toward the southwestern part of these Ltrop zones.
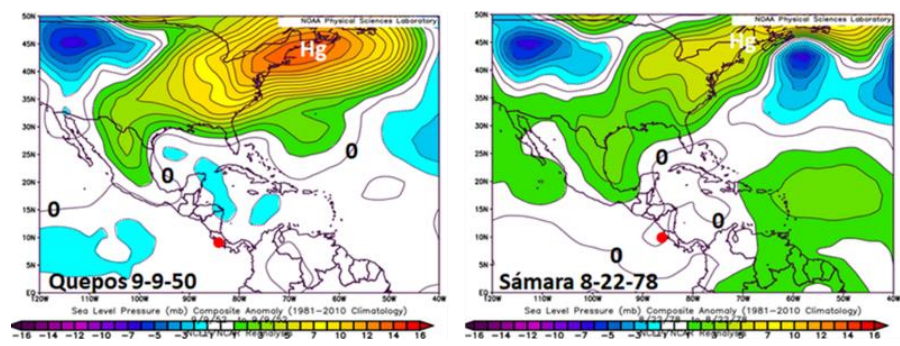

Fig. 3. Sea level pressure anomalies (hPa) for two cases in Table I showing tropical low pressure areas type Ltrop.

The two cases of earthquakes associated with Ltrop-type zones show weaker pressure anomaly fields than the Lg and $\mathrm{Ag}$ types. This is understandable since none of the disturbances had at least a tropical storm category.

Over all the epicenters of the investigated earthquakes, there were near-zero pressure anomalies during the period three days before and three days after the events. In terms of pressure anomalies, the 11 events studied occurred on the edges of the south / southwest side of three types of surface atmospheric configurations: 1) Extratropical low-pressure areas type $\mathrm{Lg}(55 \%)$; 2) High extratropical pressure type $\mathrm{Hg}$ (27\%); 3) Ltrop-type tropical low-pressure zones (18\%). Globally, $64 \%$ of epicenters were located close to the zero values of the of pressure anomalies.

There are temporal and geographic coincidences between atmospheric anomalies and the occurrence of earthquakes. One possible interpretation is that atmospheric pressure slightly alters the cortical stress field in areas with a large accumulation of tectonic stress and close to breaking, thus helping the occurrence of the event. But the precise mechanism for that to happen is still unknown. There are still tasks to be done to better understand the possible relationship between earthquakes and processes in the atmosphere, including better statistics and the quantification of friction forces on the surface of tectonic plates generated by the atmospheric pressure and wind.
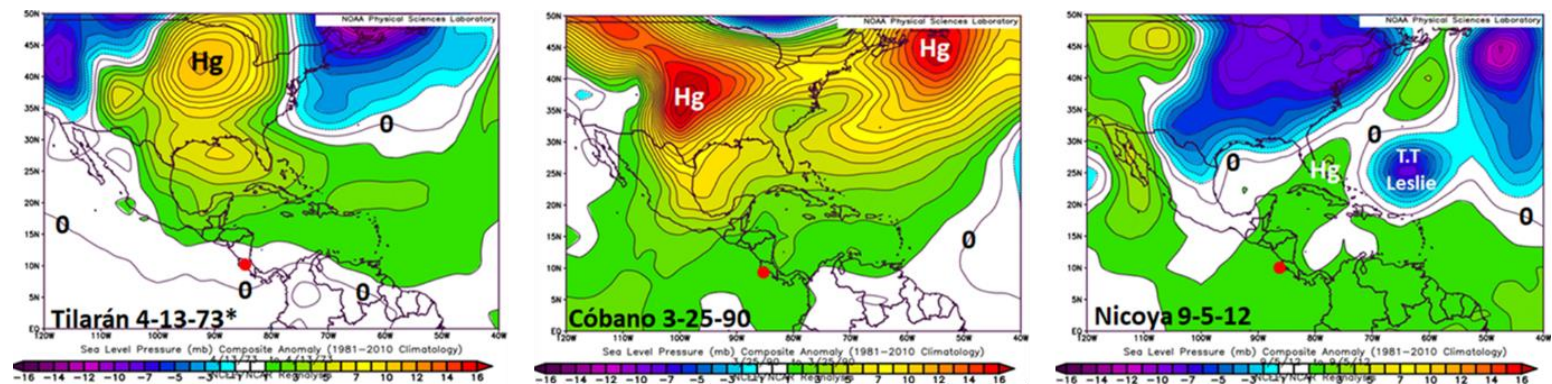

Fig. 2. Sea level pressure anomalies (hPa) for the 3 cases in Table 1 showing general high pressure areas $\mathrm{Hg}$-type. 
Laffaldano et al. [21] indicate that plate coupling can be affected by climate phenomena and mention continuous feeback mechanisms between climate dynamics and plate motions, with one dominating over the other on some occasions and vice versa.

Walker [11] found a very good correlation between episodes of intense seismicity and El Niño events and argued: "Now even more evidence calls for marine and atmospheric research to determine whether these phenomena can be linked or whether their continuing contemporaneous occurrence is merely a remarkable hoax of nature". Our research is part of those works required by Walker [11]. Our observations seem to point to links between the atmosphere and the solid earth as proposed by Walker [11], Guillas et al. [13] and Laffaldano et al. [21].

\section{Discussion}

According to the elastic rebound theory, earthquakes are caused by the accumulation and release of stress inside the earth [22]. Such stresses come from plate tectonics, movements along geological faults, and magma rises. According to Peralta et al. [23] on the earth's surface there are oscillating mechanical forces and energy transfer from external forces towards elastic systems. Newton's first law states that external forces can act on a body and change its state of motion. This happens because the external force breaks the balance of the forces acting on the object.

The results of this work confirm that during all the earthquakes studied there were atmospheric large-scale anomalies. Such anomalies include low pressure, high pressure, and tropical low-pressure systems. An outstanding fact is that $64 \%$ of the earthquakes' epicenters ( 7 epicenters) were located near the zero-value isoline of the pressure anomalies.

Four epicenters did not coincide with the zero-value curve of the anomaly, the 1983 Golfito, 1990 Cóbano, 1992 Naranjo and 2012 Nicoya. However, the values of the anomaly over such epicenters were also low, varying between 1.8 and -2.5 . In addition, the Naranjo earthquake was relatively deep, and the 2012 Nicoya earthquake was affected by another local atmospheric event, the Tropical Storm Leslie. These variants may reduce the possibility of relationship between the atmospheric anomaly and the epicentral location.

In accordance with the documentary review, the atmospheric pressure causes deformation on the earth's crust [2-5], [10], [11], [13]. Tregoning (2020, written communication) indicated that the lithosphere is deformed upwards in low pressure areas and downwards in high pressure areas Three of the aforementioned publications link the occurrence of seismicity to the atmospheric pressure [10], [11] and [13]. Zharov [12], Nishida and Takagi [14] and Fan et al. [16] attribute the occurrence of some earthquakes to atmospheric processes. Laffaldano et al. [21] indicate that the climate influences the plate motions and that there are feedback mechanisms between both processes. Zárate [1], [15] reported epicenters of earthquakes and volcanic eruptions located in the zones of zero value of the wind anomaly. This work shows earthquakes that occurred at the edges of atmospheric pressure anomalies and near-zero value isolines of such anomaly which seems to be consistent with the results of the previous works mentioned.

This work constitutes an additional contribution to the knowledge of the possible interactions or couplings between the atmosphere and the solid earth, in particular the influence of atmospheric processes in the generation of seismicity. It will be a baseline or reference for new and deeper investigations that confirm or discard what is proposed here. There is no doubt that this information will disturb other minds and will prompt new studies on this topic. Both the atmosphere and the solid earth are open fields that deserve more accurate and detailed investigation.

As has been documented in previous works, earthquakes affect the atmosphere and atmospheric events (storms, hurricanes) cause earthquakes. Atmospheric pressure causes deformation of the earth's crust. The earthquakes investigated in this work occurred at the edges of atmospheric pressure anomalies. The epicenter of $64 \%$ of them was located very close to their zero value. Earthquakes are generated by forces within the earth, but external forces could transfer energy to the elastic surface of the planet, thereby breaking the balance between the internal forces and helping to the earthquake triggering.

Earthquakes affect the atmosphere, as did the 2004 Indonesian earthquake which caused the Ionosphere to move up and down for $40 \mathrm{~km}$. Stormquakes are caused by hurricanes whose waves interact with large continental platforms or shallow flat lands. Major storms, such as the cyclonic low-pressure area (weather bomb) developed between Iceland and Greenland on December 9-11, generated seismicity detected in Japan. Measurements indicate that the earth's crust is deformed by the load of atmospheric pressure, which has been linked to seismic activity. Epicenters of seven (The sample was 11) studied earthquakes occur near the zero-value isoline of atmospheric pressure anomalies. It is possible that atmospheric pressure alters the stress field in areas with a large accumulation of tectonic stress, contributing to the earthquake triggering.

\section{ACKNOWLEDGEMENT}

Our gratitude to Oscar Aguilar for the extensive discussions on our research. Our thanks to Oscar López and Peter Barry for reviewing the manuscript.

\section{REFERENCES}

[1] Zárate E., 2018a: Acoples atmósfera-tierra sólida observados en las zonas epicentrales de grandes y pequeños sismos. Tópicos Meteorológicos y Oceanográficos, Vol 17(1), 14-40, Instituto Meteorológico Nacional, Costa Rica.

[2] G.H. Darwin F.R.S. (1882) XLVI. On variations in the vertical due to elasticity of the earth's surface, The London, Edinburgh, and Dublin Philosophical Magazine and Journal of Science, 14:90, 409-427, DOI: 10.1080/14786448208628439.

[3] van Dam T., Blewitt, G., Heflin, M., 1994: Atmospheric pressure loading effects on global positioning system coordinates determinations. Journal of Geophysical Research V 99, No. B12, p $23,939-23,950$

[4] Dong, D., Fang, P., Bock Y., Cheng, S., Miyazaki, S., 2002: “Anatomy of Apparent Seasonal Variations from GPS-Derived Site Positions Time Series", J. Geophys Res., 107(B4), 2075, doi: 10.1029/2001JB000573. 
[5] Tregoning, P., van Dam T., 2005. Atmospheric pressure loading corrections applied to GPS data at the observation level. Geophysical Research Letters, VOL 32, L22310, doi: 1029/2005GL024104, 2005.

[6] Leonard R. S., Barnes R. A., 1965: Observation of ionospheric disturbances following the Alaska earthquake. J Geophys Res, 70 1250-1253.

[7] Ding, J H, Suo, Y C, Yu, S R., 2005: Phenomena of geomagnetic and ionospheric anomalies and their relation to earthquakes (in Chinese). Chin J Space Sci, 2005, 25(6): 536-542.

[8] Liu, J., Tsai, Y., Chen, S., Lee, C., Chen, Y., Yen, H., Chang, W., Liu, C., 2006: Giant ionospheric disturbances excited by the M9.3 Sumatra earthquake of 26 December 2004. Geophysical Research Letters, Vol. 33, L02103, doi:10.1029/2005GL023963, 2006.

[9] Yu, T., Mao, T., Wang, Y., Wang, J., 2009: Study of the ionospheric anomaly before the Wenchuan earthquake. Chinese Science Bulletin volume 54, pages1080-1086. https://doi.org/10.1007/s11434-0080587-8.

[10] Namias J., 1989. Summer earthquakes in southern California related to pressure patterns at sea level and aloft. Journal of Geophysical Research, vol. 941, no. B12, pp. 17671-17679, DOI 10.1029/JB094iB12p17671.

[11] Walker, D., 1995: More evidence indicates link between El Niños and seismicity. Volume76, Issue4, 24 January, Pages 33-36. https://doi.org/10.1029/EO076i004p00033-01.

[12] Zharov V., E., 1996. Connection of the earth's rotation with the atmospheric angular momentum and the strongest earthquakes. Astronomical \& Astrophysical Transactions, The Journal of the Eurasian Astronomical Society, Volume 9, Issue 4, 1996, pages 317 327, DOI10.1080/10556799608208230.

[13] Guillas, S., Day, S., McGuire, B., 2010: Statistical analysis of the El Niño-Southern Oscillation and sea-floor seismicity in the eastern tropical Pacific. Philosophical Transactions of the Royal Society, 28 May, Volume 368, Issue 1919. https://doi.org/10.1098/rsta.2010.0044

[14] Nishida K., and Takagi R., 2016. Teleseismic S wave microseisms. Science, 26 Aug 2016 Vol. 353, Issue 6302, pp. 919-921, DOI $10.1126 /$ science.aaf7573.
[15] Zárate E., 2018b. Acoples a nivel mundial entre las placas tectónicas y la circulación general de la atmósfera antes y durante el disparo de erupciones volcánicas. Tópicos Meteorológicos y Oceanográficos, Vol 17(1), 41-58. Instituto Meteorológico Nacional, Costa Rica.

[16] Fan, W., McGuire, J., de Groot-Hedlin, C., Hedlin, M., Coats, S., Fiedler, J., 2019: "Stormquakes". Geophysical Research Letters, 46, https://doi.org/10.1029/2019GL084217.

[17] Fullerton, K., Schrenk, M., Yücel, M., Manini, E., Basili, M., Rogers, T., Fattorini, D., Di Carlo, M., d'Errico G., Regoli, F., Nakagawa, M., Vetriani, C., Smedile, F., Ramírez, C., Miller, H.,Morrison, S., Buongiorno, J., Gerdhard L. Jessen, G. Andrew D. Steen, A., Martínez, M., de Moor14, M., Barry, P., Giovannelli, D., Lloyd, K., 2021: Effect of tectonic processes on biosphere-geosphere feedbacks across a convergent margin. Nature Geoscience, No. 725, p 8.

[18] Lay, T., 2012. Why giant earthquakes keep catching us out. Nature, Vol. 483: 149-150.

[19] UCSC (Universidad of California, Santa Cruz), 2012. Study reveals complex rupture process in surprising 2012 Sumatra quake. Newscenter, Home / 2012 / September / 2012 Sumatra earthquake. https://news.ucsc.edu/2012/09/sumatra-earthquake.html.

[20] UCB (Universidad of California, Berkely), 2012. Sumatra earthquake triggered temblors worldwide for nearly a week, research shows. Home, Earth, Earth Sciences.

[21] Laffaldano, G., Husson, L., Bunge, H., 2011: Monsoon speeds up Indian plate motion. Earth and Planetary Science Letters 304 (2011) 503-510.

[22] Reid, H.F., The Mechanics of the Earthquake, The California Earthquake of April 18, 1906, Report of the State Investigation Commission, Vol.2, Carnegie Institution of Washington, Washington, D.C. 1910 (see especially pages 16-28).

[23] Peralta, J., Reyes, P., Godínez, A., 2009: El fenómeno de la resonancia. Lat. Am. J. Phys. Educ. Vol. 3, No. 3, Sept. http://www.journal.lapen.org.mx. 